\title{
Assessment Model for Construct Occupational Accident Using Confirmatory Factor Analysis
}

\author{
Nizar Jusoh ${ }^{1}$, Mohamad Wijayanuddin Ali ${ }^{1,2}$, Tuan Amran Tuan Abdullah ${ }^{1,2}$, Alias Husain ${ }^{3}$, and Zamri Chik ${ }^{4}$ \\ ${ }^{1}$ School of Chemical and Energy Engineering, Faculty of Engineering, Universiti Teknologi Malaysia, 81310, Johor Bahru, Johor, \\ Malaysia. \\ ${ }^{2}$ Center of Hydrogen Energy, Institute of Future Energy, Universiti Teknologi Malaysia, 81310, Johor Bahru, Johor, Malaysia. \\ ${ }^{3}$ Institut Pendidikan Guru Kampus Kota Bharu, Pengkalan Chepa, 16109 Kota Bharu, Kelantan, Malaysia. \\ ${ }^{4}$ Universiti Sultan Zainal Abidin Kampus Gong Badak, Gong Badak, 21300 Kuala Terengganu, Terengganu, Malaysia.
}

\begin{abstract}
The objective of this paper is to assess the occupational accident model construct using confirmatory factor analysis (CFA). The data for the study were obtained from the questionnaire survey using Likert scale rated 1 to 10 on 450 workers at the oil and gas terminal in Terengganu. CFA was used to verify the fitness of measurement model construct of occupational accident. A total of 53 significant items for the overall variables of occupational accident input were studied. In conclusion, all the variables of occupational accident construct such as engineering, human, and technical factors comply with the requirements of dimensions, validity, and reliability of the CFA requirement.
\end{abstract}

\section{Introduction}

Confirmatory factor analysis (CFA) is a special technique of factor analysis used to verify the fitness of measurement model prior to use in structure equation modelling (SEM). The analysis can validate the measurement model. This measurement model is developed on the constructs of occupational accident prudently and carefully so that the items are not redundant and do not overlap. In the oil and gas industry, CFA is used in some of the safety management and operation models. An example of CFA is in the total quality management (TQM) practice model. CFA can be built either individually or as a pooled measurement model of a particular construct. After the measurement model is developed, then SEM is used to build and analyse a comprehensive structural model. Researchers used CFA to test and assess all the constructs of occupational accident, namely engineering, technical, and human factors, where all the main CFA components, i.e., unidimensionality, validity, reliability, and fitness index can be achieved for such a measurement model.

The purpose of CFA is to assess and verify the measurement model based on theory and to determine construct validity [1]. The data involved in the study correspond to the model based on theory. CFA is used to test the reliability, validity, and unidimensionality of the measurement model [2]. It is the first step by a researcher to test the unidimensionality, validity, and reliability of the constructs [3]. Through this test, a high-value scale of its latent variable is represented as satisfying convergent validity whereas the same scale should have given low value to other latent variables characterised as fulfilling discriminant validity [1].

According to Byrne [4], CFA focuses only on the relationship between factors and items in the questionnaire known as the measurement model. It measures the extent to which the items in the questionnaire measure the predetermined variables [5]. Normally, there are two approaches of conducting CFA, namely individual CFA or pooled measurement model. Mohammad W.A. [6], stated that CFA is a tool to evaluate the fitness of latent measurement model. It helps researchers to achieve the purpose of empirical study. According to Ahmad S [7], the factor validation analysis method is used to verify significant questionnaire items for each variable (construct). It is a special form of factor analysis. CFA involves the validation of each item involved in the latent construct of the measurement model before testing the significant relationship between the two variables in the structure model. Fornell [8] stressed that before testing the significance of the relationship in the structure model, the measurement model has to comply with the established level of validity and reliability, as well as satisfy the compatibility index. The corresponding statistics for each measurement model are presented in Table 2. The results show that the measurement model of engineering, human, and technical factors have met the model's criteria conditions.

According to Zainudin [9], three aspects that need to be observed in the process of determining reliability are the internal reliability determined using the Cronbach's alpha value should be greater than 0.70 , the reliability of the constructs (CR) should exceed 0.60 , and the average variance extracted (AVE) should exceed 0.50 . Validity and reliability testing also needs to be done to determine whether the questionnaire really measures the concept that should be measured [10]. According to Cronbach [11], validity comprises of the validity of the construct and the validity of the content. Two types of validity are the validity of stability and consistency [10]. Validity also implies an agreement between two attempts to measure the same trait to the maximum by different methods [12]. And to achieve a level in which each questionnaire 
is based on a high correlation with the constructs [13]. Construct validity consists of convergent validity and discrimination validity. Both types of validity should be tested simultaneously to determine whether the questionnaire has achieved construct validity criterion [14]. Among the methods used to test the validity of the constructs is Exploratory Factor Analysis (EFA). Through the factor analysis procedure, the convergence and discrimination validities will be determined. Nunnally [15] stated three types of validity: convergent validity, construct validity, and discriminant validity. For construct validity, the measurement model has to be examined and passed all the fitness index, i.e., absolute fit index, incremental fit index, and parsimonious fit index. If the fitness index is still not achieved, modification indices (MI) are used. Zainudin [9] three aspects need to observed in the process of determining reliability, i.e., the internal reliability determined using the Cronbach's alpha value should be greater than 0.7 , the CR value should be greater than 0.6 , and the AVE should exceed 0.5 .

\section{Research methodology}

The study was conducted by distributing questionnaires to 450 workers at the oil and gas terminal at Kerteh, Terengganu using 10-point Likert scale. The determination of the total sample of the study was based on population size and can refer to Table 1 [16]. The data were analysed using SPSS 24.0 and AMOS 24.0 software.

The three main criteria in CFA are:

i. Unidimensionality: According to Zainudin [9] unidimensionality will be accepted if the construct follows the specified factor loading. The factor loading must be greater and equal to 0.5 , and for existing and stable items, the load factor must be greater and equal to 0.6

ii. Validity: Convergent validity is achieved when AVE $>0.5$ and construct validity is achieved when all the fitness indices are satisfied.

Table 1. Fitness index table for construct validity.

\begin{tabular}{|c|c|c|}
\hline Index & Test & Significance Value \\
\hline Absolute fit & GFI & $>0.90$ \\
\hline & AGFI & $>0.90$ \\
\hline & RMSEA & $<0.08$ \\
\hline Incremental fit & CFI & $>0.90$ \\
\hline & NFI & $>0.90$ \\
\hline & IFI & $>0.90$ \\
\hline Parsimonious fit & ChiSq/df & $<0.5$ \\
\hline
\end{tabular}

iii. Reliability

Table 2. Reliability table for construct reliability.

\begin{tabular}{|c|c|}
\hline Internal Reliability & Cronbach's Alpha $>0.7$ \\
\hline Composite Reliability & CR $>0.60$ \\
\hline Average Variance Extract & AVE $>0.50$ \\
\hline
\end{tabular}

\subsection{Steps to run individual confirmatory factor analysis}

For individual analysis, the researcher only performed CFA on the engineering factor construct as shown in Figure 1. The steps to run the individual or pooled measurement model are as follows:

i. Generate CFA using AMOS for measurement model.

ii. Check the corresponding compatibility index for the measurement model. If the compatibility index is not reached, check the loading factor.

iii. Remove the load factor lower than 0.60 .

iv. Eliminate low load factor one at a time.

v. Generate the measurement model after one item is broken off from the model.

vi. Check the equivalent index again. Escalate steps iii-v so that the precision index is reached.

vii. If the integration index is not reached, use the modification index.

viii. If the value of modification index exceeds 15 , there are items overlapped in the model. Eliminate the lowest load factor or label as a free parameter.

ix. Determine the Cronbach's alpha, CR, and AVE. 


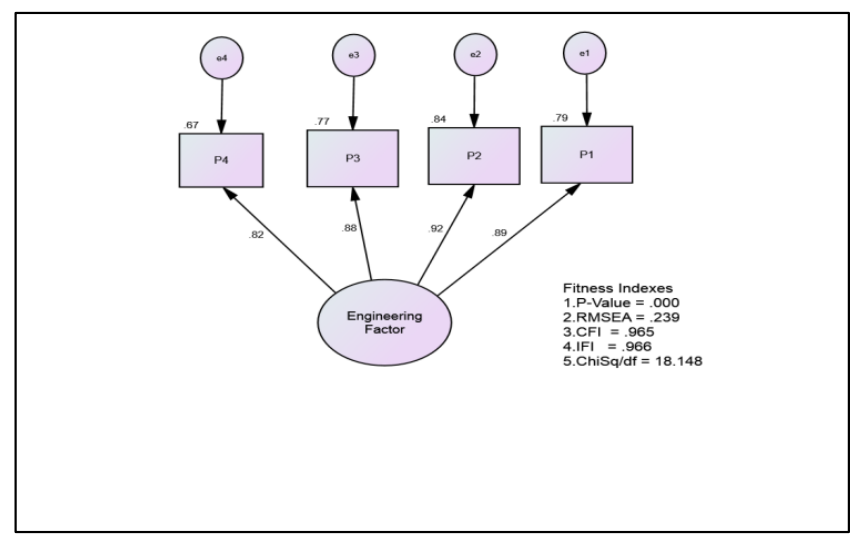

Fig. 1. The individual CFA model for engineering factor 1.

By referring to Figure 1, CFA was performed on the individual model construct of Engineering Factor 1 for the occupational accident consisting of P1, P2, P3, and P4. As shown in Figure 1, certain fitness indexes of each category for measurement model of engineering factor did not achieve the required level, which are the parsimonious fit; $\mathrm{ChiSq} / \mathrm{df}=$ $18.148>5$ (unsatisfied), the incremental fit; CFI $=0.965>0.90$ (satisfied), and the absolute fit; RMSEA $=0.239>0.08$ (unsatisfied). The use of at least one fitness model from each category to achieve the desired fitness index is recommended by Hair et al. [17]. The factor loading is greater than 0.60 . If the fitness index still does not achieve the desired value, MI should be referred. The value of MI must be higher than 15 . After that, there will be no redundant item in that construct.

Table 3. Modification indices of engineering factor.

\begin{tabular}{|c|c|c|c|c|}
\hline & & & MI & Comment \\
\hline e2 & $<-->$ & e1 & 7.564 & \\
\hline e3 & $<-->$ & e1 & 12.105 & \\
\hline e4 & $<-->$ & e2 & 14.332 & \\
\hline e4 & $<-->$ & e3 & 17.615 & MI $>15$, greatest \\
\hline
\end{tabular}

Table 3 indicates the MI for the pair of correlated errors, with the value of 17.615 (highest) is greater than 15 for e 3 and e4. The redundant items are P3 and P4. The redundancies between these two items have caused poor fit of the measurement model. In order to modify the measurement model as some fitness index does not meet the required level, the researcher has two choices. The first choice is to delete one of the two redundant items (lowest factor loading) and rerun the new measurement model, and the second option is to set these two correlated measurement errors of redundant items as a "free parameter" and rerun to obtain a new measurement model.

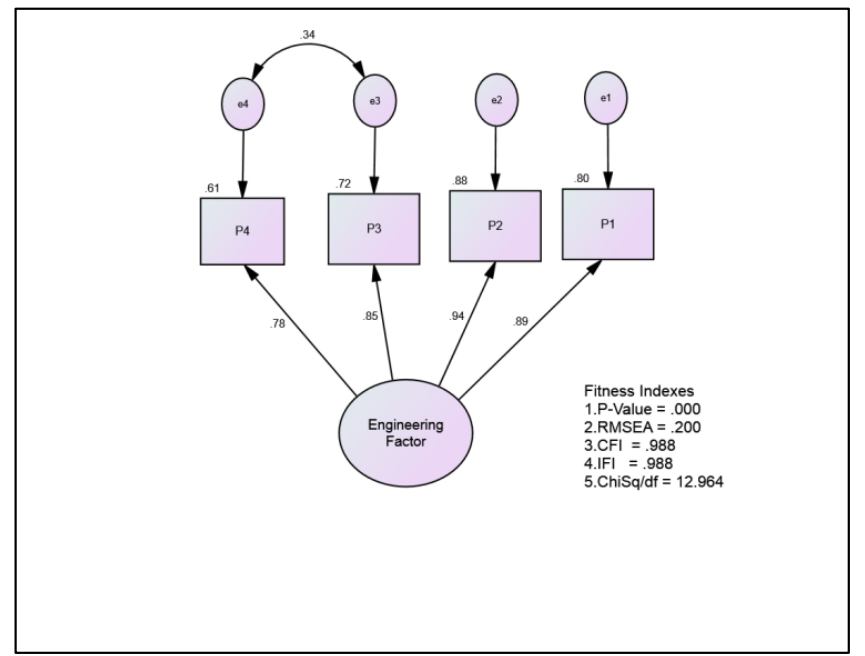

Fig. 2. Measurement model of engineering factor 2.

By referring to Figure 2, certain fitness indexes of each category for measurement model of Engineering Factor 2 still did not achieve the required level, which are the parsimonious fit; ChiSq/df $=12.964>5$ (unsatisfied), the incremental 
fit; CFI $=0.988>0.90$ (satisfied), and the absolute Fit; RMSEA $=0.200>0.08$ (unsatisfied), with all factor loadings are greater than 0.60 . The construct still has redundant items. The redundant items can be examined by inspecting the MI in Table 4.

Table 4. Modification indices of engineering factor.

\begin{tabular}{|c|c|c|c|c|}
\hline \multicolumn{2}{|c|}{} & MI & Comment \\
\hline e3 & $<-->$ & e1 & 5.894 & \\
\hline e3 & $<-->$ & e2 & 4.281 & \\
\hline e4 & $<-->$ & e1 & 9.246 & \\
\hline e4 & $<-->$ & e2 & 6.972 & \\
\hline
\end{tabular}

By referring to Table 4, all the MI are less than 15. This indicates that is no more redundant item. The reconstruction of the engineering factor measurement model will be done in pooled CFA measurement model.

\subsection{Pooled CFA measurement model of occupational accident}

The pooled CFA for measurement model can be run together after the CFA for all measurement models is computed with all the assessments for unidimensionality, validity, and reliability for all constructs, i.e., engineering, human, and technical factors as shown in Figure 3.

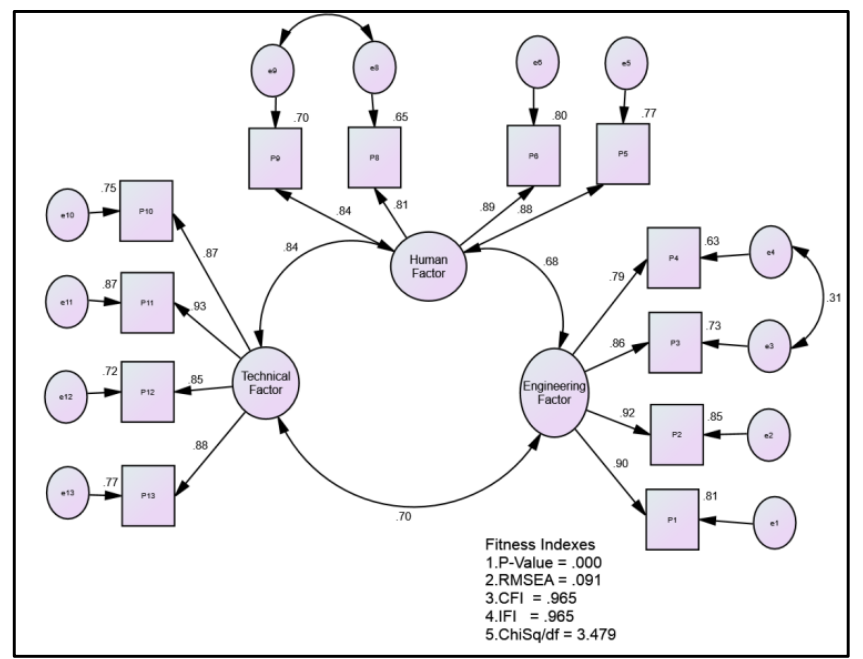

Fig. 3. Pooled measurement model of occupational accident.

As shown in Figure 3, certain fitness indexes of each category for the pooled construct did not achieve the required level, which are the parsimonious fit; ChiSq/df $=3.479<5$ (satisfied), the incremental fit; CFI $=0.965>0.90$ (satisfied), and the absolute fit; RMSEA $=0.091>0.08$ (unsatisfied). Hair et al. [5] recommended the use of at least one fitness index of each category need to be achieved. The factor loading is higher than 0.60 . Therefore, no items should be deleted. This shows that the proposed measurement model based on theory does not match the research data. In order to improve the model's fitness, the modification index from SEM analysis output is referred, the correlation for redundant items is determined, and the new pooled measurement model is run as illustrated in Figure 4. 


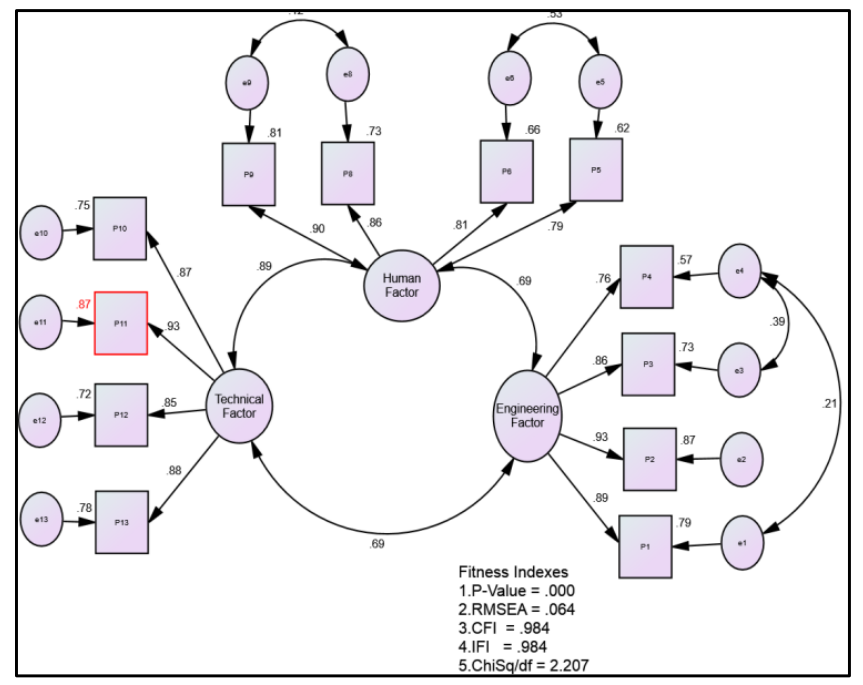

Fig. 4. Pooled measurement model of occupational accident.

\section{Results}

The CFA results for the measurement model of engineering, human, and technical factors are presented in Table 5.

Table 5. CFA results for Cronbach's alpha, CR, and AVE.

\begin{tabular}{|c|c|c|c|c|c|}
\hline Construct & Items & $\begin{array}{c}\text { Loading Factor } \\
(>0.6)\end{array}$ & $\begin{array}{c}\text { Cronbach's } \\
\text { alpha } \\
(>0.7)\end{array}$ & CR (>0.6) & $\begin{array}{c}\text { AVE } \\
(>0.5)\end{array}$ \\
\hline Engineering Factor & P1-P4 & $0.89-0.76$ & 0.93 & 0.92 & 0.74 \\
\hline Human Factor & P5-P9 & $0.79-0.90$ & 0.79 & 0.91 & 0.71 \\
\hline Technical Factor & P10-P13 & $0.87-0.88$ & 0.93 & 0.93 & 0.78 \\
\hline
\end{tabular}

Table 6. Discriminant index summary.

\begin{tabular}{|c|c|c|c|}
\hline Construct & Engineering Factor & Human Factor & Technical Factor \\
\hline Engineering Factor & 0.86 & 0.69 & 0.69 \\
\hline Human Factor & 0.69 & 0.84 & 0.73 \\
\hline Technical Factor & 0.69 & 0.73 & 0.88 \\
\hline
\end{tabular}

The results presented in Figure 4 show that all the fitness index achieved the fitness level and satisfied the measurement model requirement. For the pooled measurement model, the RMSEA is 0.064, which is lower than 0.08. The value of CFI is $0.984>0.90$ (satisfied) and ChiSq/df $=2.207<5$ (satisfied). This indicates that all categories of fitness index are satisfied and all items are significant to their constructs. Same procedures are applied to other pool measurement model, where all the fitness index of the CFA are achieved for all the constructs. The CFA results for unidimensionality, validity, and reliability for the measurement models of engineering, human, and technical factors are required prior to modelling the structural model. In assessing these criteria, the AVE and CR are also calculated as shown in Table 5. Meanwhile, Table 6 shows the results of the discriminant, where all the parameters are distinct from other constructs.

\section{Discussion}

CFA was performed to verify the unidimensionality, validity, and reliability of occupational accident construct, i.e., engineering, human, and technical factors. Each construct measures different things. Based on the analysis of validation factor, CFA has been performed to verify the credibility of the research instrument. It is found that all the correlation values are less than 0.85 . This proves that each construct measures different things [5]. It can be pointed out that the CFA's decision on the measurement model merged with a test for construct validity would give a better explanation of the quality of the measures used. Fornell [8] stressed that before testing the significance of the relationship in the structure model, the measurement model needs to comply with the established level of validity and reliability, as well as satisfy the compatibility index. According to Zainudin [9] three aspects need to be observed in the process of determining reliability. The first aspect is the internal reliability determined using the Cronbach's alpha value must be greater than 0.60 , the 
second aspect is the CR must have values greater than 0.60 , and the third aspect is the AVE should exceed 0.50 . Table 5 shows the findings of all the variables that meet the internal reliability criteria (Cronbach's alpha exceeds 0.70 , the AVE value exceeds 0.50 , and the CR value of construct reliability exceeds 0.60 ). Table 6 shows the results of the discriminant validity of engineering, human, and technical factors, where the diagonal value, i.e., the AVE square root, must be greater than the correlation between all the verifiers tested. Fornell [8] stated that in testing the validity of the problem, the square root of the AVE should be larger than the correlation between all the constructs tested for each construct. Correlation is the variance shared amongst the constructs. It can be summarised that all the required tests conducted using CFA, i.e., unidimensionality, validity, and reliability, have fulfilled the measurement model for engineering, human, and technical factors. This will enable the research to proceed to the next step with further analysis of structural equation modelling (SEM).

\section{Conclusion}

The purpose of this study is to perform confirmatory factor analysis on the constructs of occupational accident. After running the individual and pooled measurement models, the CFA for all the constructs meets the unidimensionality, validity, and reliability (Cronbach's alpha $>0.7$ ) [9]. After performing the CFA, the construct item of occupational accident construct is fit for the subsequent structural equation modelling.

\section{References}

[1] Segar, H., \& Grover, V. (1993). Re-examining perceived ease of use measurements and perceived usefulness. Decision Sciences.

[2] Jöreskog, K. G., \& Sörbom, D. (1993). LISREL 8: Structural equation modelling with the SIMPLIS command language. Scientific Software International.

[3] Bagozzi, R. P., Yi, Y. \& Phillips, L. W. (1991). Assessing construct validity in organizational research. Administrative Science Quarterly, 421-458.

[4] Byrne, B. M. (2006). Structural equation modelling with EQS: Basic concepts, applications, and programming (2nd ed.). Structural Equation Modelling with EQS: Basic Concepts, Applications, and Programming (2nd Ed.).

[5] Hair, J. F., Black, W. C., Babin, B. J., \& Anderson, R. E. (2010). Multivariate Data Analysis.

[6] Mohammad, W.A. \& afthanorhan, W. (2014). International journal of asian social science pooled confirmatory factor using structural equation modeling on volunteerism program: a step by step approach Sabri Ahmad Ibrahim Mamat contribution/originality.

[7] Ahmad, S., Nur, N., Zulkurnain, A. \& Khairushalimi, F. I. (2016). Assessing the Fitness of a Measurement Model Using Confirmatory Factor Analysis (CFA), 17(1), 159-168.

[8] Fornell, C. \& Larcker, D. F. (1981). Structural equation models with unobservable variables and measurement error: Algebra and statistics. Journal of Marketing Research

[9] Zainudin, A. (2012). Structural equation modeling using AMOS graphic. Shah Alam: Universiti Teknologi MARA Publication Centre (UPENA).

[10] Sekaran, U., \& Bougie, R. (2010). Theoretical framework in theoretical framework and hypothesis development. Research Methods for Business: A Skill Building Approach, 80.

[11] Cronbach, L. J., \& Furby, L. (1970). How we should measure" change": Or should we? Psychological Bulletin, 74(1),

[12] Campbell, D. T., \& Fiske, D. W. (1959). Convergent and discriminant validation by the multitrait-multimethod matrix. Psychological Bulletin, 56(2).

[13] Kothari, C. R. (2004). Research methodology: Methods and techniques. New Age International.

[14] Colton, D. \& Covert, R. W. (2007). Designing and constructing instruments for social research and evaluation. John Wiley \& Sons.

[15] Nunnally, J. C., \& Bernstein, I. H. (1967). Psychometric theory (Vol. 226). McGraw-Hill New York.

[16] Krejcie, R. V, \& Morgan, D. W. (1970). Determining sample size for research activities. Educational and Psychological Measurement, 30(3), 607-610.

[17] Hair, Joseph F.; Anderson, Ronald L.; Tatham, Anderson y Black, W. (1998). Multivariate Data Analysis, 